How to integrate the Good Lives Model into Treatment Programs for Sexual Offending:

\title{
An Introduction and Overview
}

\author{
Gwenda M. Willis, Deakin University, Australia \\ Pamela M. Yates, Cabot Consulting and Research Services, Canada \\ Theresa A. Gannon, University of Kent, UK \\ Tony Ward, Victoria University of Wellington, New Zealand
}

Author for Correspondence:

Dr. Gwenda Willis

The Deakin Forensic Psychology Centre

School of Psychology

Deakin University

Geelong Waterfront Campus,

1 Gheringhap Street, Geelong VIC 3217

Australia

Email: gwenda.willis@deakin.edu.au 


\begin{abstract}
The Good Lives Model (GLM) represents a new theoretical framework informing sex offender treatment programs; however, substantial variation has been observed in terms of how GLM-related ideas and practices have been applied. Integrated appropriately, the GLM offers potential for improving outcomes of programs following a cognitive-behavioral (CBT) approach and operating according to a narrow operationalization of Risk, Need, and Responsivity (RNR) principles. Conversely, misguided or otherwise poor integration could increase the very risk practitioners work to prevent and manage. The purpose of this paper is to provide an introduction and overview on how to integrate the GLM into treatment using CBT and RNR. We describe clinical implications of the GLM as they relate to program aims and orientation, assessment and intervention planning, content, and delivery.
\end{abstract}


The Good Lives Model (GLM; Laws \& Ward, 2011; Ward, 2002; Ward \& Maruna, 2007; Ward \& Stewart, 2003) represents a contemporary approach to offender rehabilitation that differs in emphasis from traditional risk management based approaches through its central focus on building client strengths rather than solely managing risk or alleviating deficits. The GLM is complementary to the Risk, Need, Responsivity model (RNR; Andrews \& Bonta, 2006; Bonta \& Andrews, 2010), and preliminary empirical research suggests that the GLM can enhance RNR-based approaches, especially in terms of improving client engagement in treatment (e.g., Gannon, King, Miles, Lockerbie, \& Willis, 2011; Simons, McCullar, \& Tyler, 2006). In brief, the GLM can accommodate the major RNR principles within a broader strength-based framework (see Ward, Yates, \& Willis, 2012). It is therefore not surprising that the GLM represents a theoretical framework informing sex offender treatment programs that is growing in popularity (McGrath, Cumming, Burchard, Zeoli, \& Ellerby, 2010). However, substantial variation has been observed in terms of how GLMrelated ideas and practices have been applied (Willis, Ward, \& Levenson, 2012). In a movement paralleling the adoption of Relapse Prevention (RP; see Laws, 1989), some treatment programs have adopted the GLM as an add-on through the addition of an extra module or assignment, while others have integrated the model in varying degrees throughout the program. Compared to RP, however, the GLM has a stronger theoretical basis supporting its integration in sex offender treatment programs (see Laws \& Ward, 2011; Ward \& Maruna, 2007; Yates, 2007; Yates \& Ward, 2007) and therefore offers potential for improving program outcomes. That said, potential improvements rest on the appropriate integration of the GLM. Misguided or otherwise poor integration could increase the very risk practitioners work to manage and prevent. The purpose of this paper is to provide overarching guidelines on how to integrate the GLM with the RNR and cognitive behavioral 
therapy (CBT) in sex offender treatment programs. As a point of clarification, the GLM and RNR represent overarching rehabilitation theories that inform treatment aims and targets, while CBT is an empirically supported treatment modality for addressing treatment targets (e.g., Hanson et al., 2002). In other words, the GLM and RNR specify what to do in treatment, and CBT informs how. The current paper is not intended as a critique of RNR nor a comprehensive description and evaluation of this rehabilitation theory (for this see Andrews \& Bonta, 2006; Ward \& Maruna, 2007).

As a theory of offender rehabilitation, the GLM contains three hierarchical sets of assumptions: (1) general assumptions concerning the aims of rehabilitation; (2) etiological assumptions that account for the onset and maintenance of offending; and, (3) practice implications arising from the first and second sets of assumptions. The focus of this paper is on practice implications, which we will describe in terms of program aims and orientation, assessment, intervention planning, content, and delivery. First, we briefly review the GLM's general and etiological assumptions to provide a basis for the practice implications that follow.

The Good Lives Model: General and Etiological Assumptions

The GLM is linked to the notions of human dignity and rights (see Ward \& Syversen, 2009), places a strong emphasis on human agency (i.e., autonomy), and takes a positive psychological approach to the treatment of sexual offenders (see Ward \& Mann, 2004). It is noteworthy that while empirical research into the effectiveness of GLM-informed interventions is in its infancy, positive psychological approaches are well supported in the clinical psychology literature (e.g., Acceptance and Commitment Therapy, see Hayes, Strosahl, \& Wilson, 2011; Motivational Interviewing, see Miller \& Rollnick, 2002). According 
to the GLM, offenders - like all human beings - value certain states of mind, personal characteristics, and experiences, which are defined in the GLM as primary human goods. Drawing from psychological, social, biological, and anthropological research, Ward and colleagues have proposed eleven classes of primary goods ${ }^{1}$ : (1) life (including healthy living and functioning); (2) knowledge; (3) excellence in play; (4) excellence in work (including mastery experiences); (5) excellence in agency (i.e., autonomy and self-directedness); (6) inner peace (i.e., freedom from emotional turmoil and stress); (7) relatedness (including intimate, family, and friend relationships); (8) community; (9) spirituality (in the broad sense of finding meaning and purpose in life); (10) happiness; and, (11) creativity (e.g., Purvis, 2010; Ward \& Gannon, 2006). Whilst it is assumed that all human beings seek to attain all primary goods to some degree, the weightings or priorities given to specific primary goods reflect individuals' particular values and life priorities.

While primary goods represent those things for which people strive, instrumental or secondary goods represent the concrete means of achieving these ends, and take the form of approach goals. That is, secondary goods are those activities in which individuals engage in the pursuit of primary goods - what people do in order to achieve these goals in life. For example, the primary good of relatedness might be satisfied through spending time with friends and family, meeting new people, or being in an intimate relationship. The primary good of excellence in play might be achieved through involvement in sport or other hobbies.

Effective sexual offender treatment involves targeting criminogenic needs, or dynamic risk factors. Within the GLM, both criminogenic and noncriminogenic needs exert

\footnotetext{
${ }^{1}$ Note that this is a recent change from the initial 10 classes of primary goods identified by Ward \& Stewart (2003).
} 
their influence on, or through, secondary goods. For example, relying on antisocial peers to achieve the good of relatedness or using drugs to relieve negative moods and meet the primary good of inner peace, are examples of instrumental or secondary goods that also represent dynamic risk factors. Thus, criminogenic needs are conceptualized as barriers towards satisfying primary goods in non-harmful ways.

The GLM assumes that all humans fashion their lives around their core values and follow some sort of (often implicit) Good Life Plan (GLP), however rudimentary. Offending relates either directly or indirectly to the pursuit of primary goods and is considered to result from flaws in an individual's GLP. Importantly, these flaws relate to problems with secondary goods - the activities/means individuals use to achieve primary goods - and not the primary goods themselves (Ward \& Gannon, 2006; Ward \& Maruna, 2007; Ward, Yates, \& Long, 2006). The GLM defines four different flaws, which often co-occur and are therefore not mutually exclusive. In no particular order, the first flaw is the use of inappropriate or harmful means to obtain primary goods. For example, an individual may seek out the good of relatedness through sexual offending against a child. A second flaw is a lack of scope in a GLP, in that an individual's GLP may be overly narrow and neglect important goods. For example, an individual might expend considerable amounts of time engaged in activities to fulfill the good of excellence in work, and leave little or no time for satisfying the goods of relatedness and happiness. A third flaw is when an individual experiences conflict or a lack of coherence between valued primary goods and/or in the secondary goods (i.e., means) used to secure primary goods. Attempting to secure autonomy by dominating a partner (itself a problem with means), for example, conflicts with satisfying the good of relatedness through the same relationship. The final flaw is a 
lack of internal and/or external capabilities to satisfy primary goods. Problems with internal capacity are internal to the individual and include a lack of knowledge and/or skills, for example poor problem-solving or affect regulation skills. Problems with external capacity are external to the individual and include a lack of environmental opportunities, resources, and supports, for example lacking pro-social associates and employment opportunities. Criminogenic needs are evident in problems with internal and external capacity, consistent with their conceptualization in the GLM as barriers towards satisfying primary goods in nonharmful ways. For example, antisocial orientation, a dynamic risk factor for general, violent, and sexual recidivism (e.g., Andrews \& Bonta, 2006; Hanson \& Morton-Bourgon, 2005), might represent a barrier towards fulfilling the primary good of autonomy through frequent sentences of incarceration. Similarly, poor emotion regulation - again a dynamic risk factor for all types of recidivism (Bonta \& Andrews, 2010) - might block attainment of inner peace. The aims of treatment according to the GLM are to assist clients to obtain primary goods in non-harmful ways, overcome flaws in their GLP, and reduce and/or manage their risk to reoffend.

Yates and colleagues have produced a series of resources describing the GLM approach in detail (Yates, Kingston, \& Ward, 2009; Yates \& Prescott, 2011; Yates, Prescott, \& Ward, 2010), and a small but increasing number of papers have been published describing treatment programs that have integrated the GLM to varying degrees (e.g., Gannon, et al., 2011; Harkins, Flak, \& Beech, in press). What is missing, however, is a set of overarching guidelines for incorporating the GLM throughout a treatment program, which is the rationale for the current paper. In the sections that follow we describe clinical implications arising from the GLM from the beginning to the end of a treatment program: program aims 
and orientation, client assessment, intervention planning, program content, and program delivery. It is important to note that the GLM is a rehabilitation framework that is intended to supply practitioners with a foundation from which specific, empirically-supported interventions such as cognitive-behavioral treatment techniques are applied (Ward \& Maruna, 2007; Yates \& Ward, 2008). Thus, what follows is not a program manual but rather a set of overarching guidelines, which can be used to form the basis of a treatment program that is consistent with the GLM (and RNR and CBT).

How to Integrate the GLM

\section{Program Aims and Orientation}

Treatment programs for sexual offending are typically tasked with one aim: to reduce the likelihood that a treated offender will reoffend. While this aim is clearly important and the very reason treatment programs exist, on its own it is likely to prove insufficient to motivate clients to engage in treatment, particularly with the sole focus on clients' deficits and risk management (Ward, Melser, \& Yates, 2007; Yates, 2009). Given the importance of client engagement in treatment (Marshall \& Burton, 2010), program aims including how these are communicated to clients - need to hold substantial appeal. To reiterate, a central aim of rehabilitation according to the GLM is to build client capacity to live a satisfying life that does not involve harming others. At an operational level, this means framing treatment as something that will assist clients to attain a better life and reduce life problems in addition to living an offense-free life (Yates \& Prescott, 2011; Yates, et al., 2010). This involves such tasks as explicitly describing treatment as something that will benefit the client and as an exercise in which the client will be an active agent in determining what primary goods he/she wishes to attain, and how he/she plans to attain them. The language used to convey this approach is also important. At a practical level, this 
requires ensuring that the title of a program and any associated client workbooks, treatment consent forms and/or contracts, and any other induction/orientation materials are consistent (or at least not at odds with) these dual aims. Programs and workbooks incorporating words and phrases such as "stop," "relapse prevention," "safer communities," and the like into their titles typically accommodate only one of these aims, while the commonly used "sex offender treatment program" does not directly capture either aim and rather assigns a label to clients that goes against the aims of GLM-based treatment.

Given the GLM's grounding in human rights, in an ideal world clients should enter treatment of their own accord. However, the reality in many jurisdictions is that treatment is mandatory, and in other jurisdictions clients must complete treatment before being considered for release from prison. In either case, processes by which clients commit to treatment can still integrate a GLM approach. Consent forms or treatment contracts should outline the dual aims of treatment, and their contents should link directly to these aims. To illustrate, it is common for treatment contracts to contain a list of behaviors in which clients are prohibited from engaging throughout the course of treatment. Examples include being on premises that sell alcohol, consuming alcohol or drugs, associating with certain individuals, and so forth (Willis, et al., 2012). Utilizing the GLM, the rationale for such guidelines in terms of their fit with the dual aims of treatment (or requirements of probation/parole, as the case may be) should be communicated clearly. This is best achieved through framing treatment requirements in terms of approach goals, which research shows are more engaging than avoidant goals (see Mann, Webster, Schofield, \& Marshall, 2004; Ward \& Maruna, 2007). For example, clients might be encouraged to attend each treatment session alert and sober so they are best able to benefit from, and contribute to, program sessions. Sub-clauses to this guideline might include avoidant goals 
(e.g., not attending sessions while intoxicated), but the overarching guideline is approachoriented and linked with the broader aims of treatment. That is, clients are reminded that treatment is about improving their lives while reducing their risk to re-offend, and that achieving these dual aims requires their active and concerted participation. Similarly, clients might be encouraged to surround themselves with positive pro-social influences who are best able to help them achieve their treatment and life goals. Sub-clauses might include avoiding contact with children and/or antisocial associates, depending on the nature of an individual's offense.

Ideally, program guidelines or operating principles are developed collaboratively with all group members and are mutually agreed upon, rather than requiring clients to sign a list of pre-determined rules. Group guidelines often take the form of a list of "group rules" that are posted in the program room. Within the GLM framework, it is recommended that this list be developed collaboratively with clients rather than pre-determined by the therapist. In this way, not only is the collaborative nature of treatment reinforced from the beginning of treatment, but investment in the group process increases and is reinforced by participants themselves, clients take ownership of the group rules, and the functioning of the group becomes a personally meaningful task toward which clients work together. In summary, from the first meeting with a client and throughout introductory sessions, it is important that the dual aims of treatment are communicated clearly such that clients enter treatment with the knowledge that the program is designed to assist them develop skills to live a personally meaningful, offense-free life.

\section{Client Assessment}

Given that the GLM builds on what is already known about effective rehabilitation, assessment procedures common to RNR-based programs are also used under the auspices 
of the GLM. An empirically informed assessment of risk level using static (e.g., Static-99R; Helmus, Babchisin, Hanson, \& Thornton, 2010) and dynamic (e.g., Stable-2007; Hanson, Harris, Scott, \& Helmus, 2007) measures determines the intensity of intervention required, while assessment of dynamic risk additionally helps identify treatment targets (Yates, et al., 2000; Yates, et al., 2010). Assessment of responsivity factors requires consideration of cognitive ability, learning style, personality, mental health, culture, and other characteristics unique to individual clients that help inform the nature and delivery of interventions in order to enhance their efficacy (Andrews \& Bonta, 2006). This also includes any supplemental assessment with respect to additional interventions that may be required (e.g., medication management). With respect to responsivity factors, many treatment programs focus on motivation, given that this is typically assumed to be low among sexual offenders (Thornton, 1997). The GLM is especially amenable to enhancing motivation to participate in treatment, with its focus on approach goals and what the client will personally gain from treatment in order to attain a better life (Yates, 2009; Yates et al., 2010). The use of the GLM to enhance motivation, as measured by improved treatment completion rates and reduced dropout rates, has been demonstrated in research (Simons et al., 2006).

In addition to evaluation of risk, need, responsivity, and other pertinent individual factors, GLM-informed assessment also involves identifying a client's heavily weighted primary goods (i.e., what is most important to them in life), how they have gone about attaining these goods, and identifying problems or flaws in a client's past and current GLP, with an emphasis on those problems that have contributed to sexual offending and to life problems. Heavily weighted primary goods reflect a client's values and priorities in life. Their identification is both forward and backward looking, with time of offending used as a reference point to assess for heavily weighted goods in the past. Heavily weighted goods 
are identified through asking increasingly detailed questions about a client's past and current core commitments in life and valued day-to-day activities and experiences. Important goods on which individuals may have given up earlier in life (e.g., because of lack of skills or opportunity) may be assessed from examination of early GLPs at various points in the individual's life (Yates \& Prescott, 2011).

Importantly, the process of identifying heavily weighted goods should be one of extraction, whereby the clinician identifies the goods evident in client's responses through reflective listening, paraphrasing, and summarizing - rather than presenting clients with a list of primary goods and asking them to identify the relative importance they place/placed on each. This is because the concept of primary goods is relatively abstract and clients will be more likely to focus on secondary goods - the means used to attain primary goods from which the primary goods must be extracted and inferred. Moreover, the process of identifying and labeling what an individual values might be foreign to clients, as can be the names of the primary goods themselves, although it is noted that these names have recently been revised for application in practice with clients (see Yates \& Prescott, 2012). A structured interview to assess for heavily weighted goods is provided in Yates, Kingston, et al. (2009), and examples of clinician-client dialogue demonstrating the process of identifying heavily weighted goods through clinical interview can be found in Yates et al. (2010). Pen and paper questionnaires are also available that can provide collateral sources of information in helping to identify a client's heavily weighted goods, such as the Personal Concerns Inventory (Sellen, McMurran, Cox, Theodosi, \& Klinger, 2006) and the Quality of Life Inventory (Frisch, Cornell, Villanueva, \& Retzlaff, 1992). Not only do heavily weighted goods form the basis of clients' intervention plans (described in the next section), their identification provides an additional responsivity consideration. To illustrate, in their 
program for mentally disordered clients, Gannon et al. (2011) describe encouraging one client to supplement group tasks and assignments with his own drawings and pictures in recognition of the importance he placed on creativity.

In practice, GLM-based assessment involves assessing the weight or value that individuals place on all 11 primary goods (thereby assessing the full range of primary goods), identifying past and current secondary goods (i.e., concrete ways through which primary goods are sought), and any problems experienced attaining each good (i.e., flaws). For example, assessment includes evaluation of how important it is (or was) for a client to have a specific primary good in his/her life, whether he/she would like to have more of this in his/her life, and whether the importance of a particular primary good has changed over time. To identify secondary goods, assessment includes identification of what the individual has done in the past, or does presently, to achieve the primary good, identification of strategies that have worked well and those that have not worked to achieve the good, and how the ways they have gone about attempting to achieve the primary good have resulted in harm to others. Assessment of secondary goods also helps identify clients' strengths (i.e., which primary goods he/she is currently attaining through appropriate means) as well as areas in a client's life that are/were lacking in fulfillment. Thus, assessment can identify the strategies individuals may use to attain a primary good that are effective and that do not result in harm caused to others or to life problems. For example, effective emotion regulation skills or indicators of excellence in work might become evident for some clients, and are skills upon which treatment can build. In addition, throughout this assessment process, problems with means, scope, conflict, and capacity in a client's GLP also begin to emerge.

Thus far we have described the process of identifying heavily weighted goods and assessing the full range of primary goods - including the means used in the past and 
currently to attain each good. Throughout this process, and especially for clients who followed a direct route to sexual offending (i.e., their offending represented an explicit or obvious attempt to satisfy one or more primary goods), problems in a client's GLP that contributed to their offending will begin to become evident. Analyzing the offense progression can assist in providing a richer understanding of the primary goods implicated in, or associated with, sexual offending, including explicitly identifying problems with means, scope, conflict, and capacity in a client's GLP. In contrast to RP methods which focus on deficits and problems in the lead up to an offense (Ward \& Hudson, 1998), analyzing the offense progression under the auspices of the GLM requires identifying how an individual's actions at the time of their offense related to their pursuit of primary goods. That is, it is a process of understanding what they were trying to achieve via offending and the purpose that offending served for them in relation to attaining primary goods. Thus, there is an underlying assumption that offending resulted from problems in the pursuit of primary goods, rather than simply deficits inherent in the individual. Furthermore, striving to attain particular primary goods, even through offending, is validated in that it is explicitly stated that the problem does not lie in the desire to attain a particular primary good, but in the ways in which the individual sought to attain the good. Intervention then reinforces the pursuit of the good while assisting individuals to attain these in ways that do not cause harm or result in life problems. We recommend that this component of assessment is continued through an early program module or assignment designed to assist clients to develop a full understanding of problems in their GLP that contributed to their offending. In this way, client autonomy is recognized through a collaborative approach to assessment. Clients with compromised intellectual functioning and/or a more complex and indirect GLM pathway to 
offending might require additional support to develop an understanding of the links between their offending and the GLM (see Gannon et al., 2011).

Structured assessments of offenders' pursuit of goods and their constitutive problems (GLP flaws) have been developed (see Yates, Kingston, et al., 2009), the initial research for which is promising in terms of psychometric properties (see Kingston, Yates, Simons, \& Tyler, 2009; Yates, Simons, Kingston, \& Tyler, 2009). A comprehensive assessment provides clinicians with the beginnings of a case formulation, which summarizes and integrates key information collected through assessment and provides a foundation for intervention planning. A GLM-informed case formulation describes the relationship between the pursuit of primary goods and offending, details specific flaws in a client's GLP (i.e., problems with means, scope, conflict, and capacity), highlights strengths (i.e., appropriate means, or secondary goods, the client previously and/or currently uses to attain primary goods), and links with self-regulation (see Ward, et al., 2006; Yates \& Kingston, 2011; Yates, et al., 2010).

\section{Treatment/Intervention Planning}

GLM-based intervention plans provide a roadmap for working towards the dual aims of treatment - enhanced well-being and reduced risk - and form the basis of a futureoriented GLP, the life toward which clients will work during treatment. Importantly, intervention plans are dynamic in that they are refined as treatment progresses and as clients build strengths and competencies to satisfy primary goods in pro-social ways. Consistent with the GLM's focus on client agency, the intervention planning process should be one that is collaborative and in which clients participate in setting treatment goals. An assessment feedback session might be used to check that the clinician has an accurate understanding of a client's heavily weighted primary goods, their relationship to offending 
behavior and life problems, and client strengths. Clients are informed that treatment aims to equip them with skills and resources to live a life that is consistent with their core values and life goals (i.e., heavily weighted primary goods) while reducing their likelihood of reoffending. An important task for clinicians is to feed back results of dynamic risk assessment and explain results to clients in terms of how these factors are currently blocking or otherwise interfering with pro-social attainment of prioritized goods, and how these are linked to offending. In this way, from the outset of a treatment program, the dual aims of treatment in terms of risk reduction and well-being enhancement are made explicit to clients. As indicated above, this is expected to assist in increasing motivation to undertake treatment.

GLM-based intervention plans are individualized such that they centre on attainment of a client's heavily weighted goods and reduction or management of criminogenic needs. Accordingly, clients' prioritized goods on which they will work in treatment should be specified in the treatment plan, together with dynamic risk factors that frustrate goods attainment and increase risk. Some clients will enter treatment with explicit goals in relation to secondary goods while other clients might enter treatment with no such goals. Any appropriate secondary goods (i.e., strengths) clients have in place at the beginning of the program to satisfy primary goods should be acknowledged, reinforced and incorporated into treatment plans, together with future-oriented secondary goods or goals the client might have in relation to fulfilling heavily weighted goods. For example, relatedness represents a commonly prioritized primary good among sexual offenders (e.g., Barnett \& Wood, 2008; Kingston, et al., 2009; Willis \& Ward, 2011). Clients might enter a program with explicit goals associated with this primary good, such as to make more friends, re- 
connect with family, find a romantic partner, and so forth. These goals represent potential secondary goods, and are therefore included in the treatment plan with respect to attaining the primary good of relatedness. The initial intervention plan incorporates sub-goals or steps towards achieving the larger goal, which will necessarily include addressing criminogenic needs. Depending on the individual client, criminogenic needs that will require targeting might include deviant sexual arousal, using sex as a coping strategy, or sexual preoccupation as, in addition to representing dynamic risk factors, these can contribute to (i) blocking the attainment of relatedness, and/or (ii) attaining this good via offending. Importantly, not all sub-goals or steps towards goal attainment will be related to treatment per se. Consider the example of an individual prioritizing the primary good of excellence in work, and having the explicit goal of becoming a mechanic. This secondary good or goal is included in the client's intervention plan under the primary good of excellence in work because it will make a crucial contribution to the client's subsequent level of well-being and GLP. Sub-goals, or steps towards attaining the goal of becoming a mechanic, might include addressing criminogenic needs (e.g., impulsivity) as well as noncriminogenic needs (e.g., participating in vocational training). Thus, the intervention plan includes such aspects and, given the holistic nature of GLM-informed intervention planning, the term "intervention plan" rather than "treatment plan" is used. While treatment programs might not be resourced to directly assist clients with noncriminogenic needs, their inclusion in intervention plans assists clients to appreciate how various aspects of rehabilitation cohere and the importance of specific goods to the individual in his/her life. Moreover, the inclusion of noncriminogenic needs in intervention plans facilitates the sharing of intervention plans with other services or people with whom the client is engaged (e.g., support people, probation/parole officers, etc.), and allows others to assist the client to 
work towards implementing his/her GLP. Furthermore, the inclusion of such plans allows treatment to explicitly include pro-social approach goals toward which the client can work and practice and which will ultimately assist in improving well-being.

\section{Intervention Content}

The GLM is an overarching rehabilitation framework and as such, does not prescribe specific intervention content. Moreover, by virtue of the GLM's focus on individualized GLM intervention plans, "one-size-fits-all" treatment manuals are not complementary to a GLM approach. There has been much debate about the use of manuals in treatment programs for sexual offending (e.g., Mann, 2009; Marshall, 2009). Several authors advocate the use of treatment guides rather than treatment manuals (e.g., Marshall, Marshall, Serran, \& O'Brien, 2011), while others suggest more comprehensive materials in order to ensure adherence to, and achievement of, important treatment targets (Yates, et al., 2000). In whatever format, a structured guide enables greater tailoring of interventions to match an individual's unique intervention plan, and is thus more consistent with a GLM approach than a rigidly structured treatment manual. It is noted that some structure is required, however, in order to ensure that important treatment targets are addressed (e.g., empirically-supported dynamic risk factors) and that program integrity is high such that treatment effectiveness is maximized (Gendreau, Goggin, \& Smith, 1999). In this section we provide guidelines for incorporating a GLM approach into intervention content. It is beyond the scope of this paper to provide specific guidelines and we refer interested readers to Yates et al. (2010) for an elaboration of what GLM-guided treatment could look like. In brief, this includes clear general goals and suggestions concerning the activities, strategies, and interventions that are most likely to result in constructive change, while tailoring how these specific interventions apply to 
individual clients. For example, treatment may include modules addressing the targets of general self-regulation, sexual self-regulation, relationships and intimacy, and so forth. Within these modules, core constructs are explored based on important risk factors and treatment targets, such as impulsivity, the use of sex as a coping strategy, and healthy and unhealthy relationships. In practice, therapists ensure these key constructs are addressed, while acknowledging that their manifestation, and the strategies required to manage these risk factors, will be unique to each client. Treatment thus ensures that it addresses important areas, while allowing the flexibility for clients to understand how each applies to their lives and the most appropriate and effective strategies to manage themselves in each area.

Initial group treatment sessions often involve establishing group norms or operating principles, group member introductions, and an orientation to treatment. Utilizing the GLM, group member introductions may involve each participant sharing a personal strength and something they want to work on in treatment, and anything else about themselves that they want to disclose. This is in contrast to the procedure adopted in many treatment programs in which introductions are solely or predominantly focused on clients' offenses, sentencing information, and criminal history. In terms of orienting clients to the GLM, a detailed description of the GLM is not necessary, although a brief description should be provided in order to reinforce the notion that intervention is an activity designed to enhance clients' well-being (see the "For Clients" section of www.goodlivesmodel.com for an example of a client friendly description of the GLM). The core message to be communicated is that sexual offending is considered to be the product of problematic attempts to satisfy what is important in clients' lives or the result of an otherwise problematic life plan. In this way, clients are reminded that, like all human beings, they 
have a set of heavily weighted primary goods or values (i.e., life goals) but that problems have arisen in their attempts to attain these. Treatment aims to address those problems and, more importantly, to develop skills to live a personally meaningful, offense-free life.

It is expected that modules common to RNR-based programs are included in any GLM consistent program, including modules on emotion regulation, social and intimacy skills, problem-solving skills, sexuality (including arousal reconditioning), understanding offending and self-regulation. However, within the GLM framework, CBT techniques are "wrapped around" individuals' life priorities or overarching goods, which we expand on below.

Enhancing consistency of treatment modules and assignments targeting criminogenic needs to the GLM is primarily achieved through incorporating approachoriented goals into the aims of each module, and linking each to goods fulfillment. As highlighted by Ward, Mann, and Gannon (2007), most modules typical of RNR-based sex offender treatment programs are associated with an overarching primary good. Consider a module that focuses on understanding offending and restructuring offense-supportive beliefs. Utilizing the GLM, the aim of this module would be to assist clients to develop an understanding of a simplified GLM-based case formulation. More specifically, the aim is for clients to obtain a clear understanding of how problems in their GLP contributed to their offending, and more specifically, how associated thoughts, feelings, and behaviors led to an offense. Thus, the aim of the module is approach-oriented (to gain understanding) and is linked to goods fulfillment (knowledge). By way of contrast, if the aim of such a module is for clients to identify and restructure offense-related cognitive distortions and, in doing so, to accept full responsibility for their offending, the intervention would be inconsistent with 
a GLM approach because this aim is not associated with goods promotion (this is a societal/moral aim, not necessarily a client goal at this early stage of a program). Similarly, a module addressing relationships that focuses on intimacy deficits and avoiding problematic relationships would be inconsistent with a GLM approach, which would focus on clients' strengths in this area and explicitly on how to seek out and establish satisfying partnerships.

Reconditioning or managing deviant sexual arousal constitutes an important component of any treatment program, given that deviant sexual interests have consistently predicted re-offending in meta-analyses (Hanson \& Bussière, 1998; Hanson \& MortonBourgon, 2005) and moreover, that several approaches for modifying deviant arousal have been documented (see Marshall, O'Brien, \& Marshall, 2009). For those clients whose deviant sexual arousal represents a dynamic risk factor, a risk management approach is essential given the importance of this factor. As such, CBT interventions typically utilized in treatment are included in a GLM approach. What is different is that, in utilizing the GLM, it is also important to develop approach goals with respect to appropriate sexual fantasy, arousal, and behavior. More specifically, it is important that clients enter arousal reconditioning treatment with a clear understanding regarding how it will assist them to satisfy their heavily weighted goods and implement a future GLP - that is, that this intervention is not solely avoidance-based nor related only to risk management. The primary goods associated with this module will vary between clients, depending upon the origin of deviant sexual arousal - be it in pursuit of intimacy (relatedness), emotion regulation (inner peace) or physical satisfaction (happiness) (e.g., Ward, Mann, et al., 2007). Thus, in addition to specific behavioral techniques aimed at reconditioning deviant sexual arousal, it is important that clients are equipped with the skills and knowledge to secure the 
underlying goods using healthy, adaptive means. Other modules common to RNR-based treatment programs and their associated goods include affect regulation, associated with inner peace and happiness; and relationship skills, associated with relatedness, community, and agency (Ward, Mann, et al., 2007). Utilizing the GLM, it is essential that these links are made explicit throughout a program, such that clients can appreciate how each module or assignment can assist them develop skills to satisfy primary goods in pro-social ways.

The final phase or module of a GLM-consistent treatment program involves assisting clients to develop and implement a future-oriented GLP. GLPs contain a detailed set of plans to assist clients to satisfy their heavily weighted goods in ways that are incompatible with future offending. Thus GLPs revolve around the pro-social attainment of clients' heavily weighted goods, and contain realistic secondary goods to satisfy the primary ones. GLPs contain immediate, medium, and longer term foci, as appropriate. Attention to a client's social environment becomes increasingly important at this point of a program, as it is crucial that client plans are realistic and achievable in the environments in which they intend to live. Release planning (e.g., considering housing, employment, and social support) therefore becomes a key intervention component for prison or residential programs, which is supported by empirical research documenting the importance of release planning in reducing sexual recidivism (Schoones, Willis, \& Grace, in press; Willis \& Grace, 2008, 2009; see also Yates, et al., 2000). A GLP will necessarily attend to areas of risk, but as in the initial intervention plan, risk factors are conceptualized as potential obstacles blocking goods fulfillment in addition to being intervention targets in and of themselves. At this point in a program, clients would have developed skills to address risk factors, which can be incorporated into the GLP accordingly. For example, deviant sexual interests might 
represent an obstacle towards securing the primary good of relatedness. Through treatment, a client might have learned to recondition or manage deviant arousal patterns; however, the potential for deviant sexual arousal to recur must be acknowledged, together with strategies to implement in the event of a recurrence. Additionally, by virtue of having developed appropriate approach goals to meet sexual needs, clients possess additional strategies to attain the primary good associated with these needs in pro-social, non-harmful ways. This approach differs from a traditional relapse prevention plan, in which deviant sexual arousal would be listed as a warning sign together with a list of "coping skills" to employ in the event of a recurrence. Utilizing the GLM, deviant sexual arousal is incorporated into a GLP as a sign or indicator that a client might not be attaining an associated good (e.g., relatedness, inner peace, or life). A risk management plan is also included, although this is formulated as part of a broader overall self-regulation plan (Ward, et al., 2006; Yates, et al., 2010). Rather than focusing on "coping skills," clients develop various approach-oriented strategies they can implement to both reduce the potential for recurrence and to employ in the event that acute deviant sexual arousal occurs. The point of difference is twofold: to include risk factors and strategies in a GLP and to specify the reasons for their inclusion (i.e., attaining heavily weighted goods versus managing risk by dealing with high-risk situations). By extension, in the community, supervision also addresses these two elements: monitoring and managing risk and ensuring that clients are working toward attaining primary goods (Yates \& Prescott, 2011; Yates et al., 2010). Intervention Delivery

Intervention delivery is concerned with therapists' and others' (e.g., parole and probation officers') attitudes and approaches to intervention, language used in reference to clients, and the procedural aspects of treatment programs. Central to the ethical 
commitments of the GLM is the acknowledgement that individuals who have engaged in sexually harmful behavior are "people like us" (Laws \& Ward, 2011). Like us, clients have the right to be treated with dignity and respect. At an operational level, this includes considering how a client wishes to be addressed, taking into account any cultural or other specific responsivity issues, and displaying positive therapist characteristics in all interactions with clients. Positive therapist characteristics include displays of warmth, respect, praise, empathy, and appropriate humor, and have been empirically associated with treatment change (e.g., Marshall, 2005). Like other practice implications of the GLM (e.g., attention to a client's social environment), attention to positive therapist characteristics is not something unique to the GLM, but fits particularly well with the GLM rehabilitation framework. Additionally, a unique feature of the GLM is its comprehensive and holistic framework, which enables it to seamlessly integrate aspects of good clinical practice such as paying attention to process and therapist variables, as well as giving direct consideration to areas often overlooked in sex offender treatment (e.g., clients' values and well-being). By way of contrast, hostility, negative labeling of the client, and the use of confrontation are all inconsistent with a GLM approach and do not represent empirically supported means of promoting change (Laws \& Ward, 2011). Also central to the ethical commitments of the GLM is recognition of client agency and autonomy, which has several implications for the operational aspects of a treatment program, including a collaborative and transparent approach to assessment, intervention planning, and intervention content. This means that results of assessment and any reports written about clients should be reviewed with clients and their input sought as appropriate.

Throughout this paper, we have highlighted the importance of tailoring interventions to each client's unique intervention plan. While there will be overlap between group 
members' criminogenic needs, the nature and intensity of interventions required will differ between clients depending on which criminogenic needs present the greatest barriers to implementing their GLP. Additionally, while noncriminogenic aspects of intervention plans might not be explicitly targeted in a treatment program, "check-in" discussions at the beginning of groups can be used to discuss such issues and provide a forum to encourage clients as they go about implementing their GLPs outside treatment sessions (e.g., through reinforcing pro-social attempts to satisfy primary goods). As clients address criminogenic needs or obstacles that have previously hindered goods attainment, intervention plans are updated to reflect a client's progress and the direction his/her future-oriented GLP is taking.

An additional consideration concerning intervention delivery is the environmental context in which programs operate, including the treatment room and its surroundings. In recognizing the GLM's commitment to client agency, care should be taken in the basic setup of the treatment room such that the therapist is not seen as superior to clients, nor seen as a teacher. To illustrate, sitting in a circle with clients communicates a sense of equality, respect, inclusion, and collaboration, whereas sitting behind a desk at the front of the room communicates the idea that the therapist is a teacher or an expert, that the group room is a classroom, and that clients are passive recipients of information. While the therapist might sometimes take on a teaching role, treatment is an exploratory process in which clients are active participants, and the therapist is generally a guide, not a teacher. There are several ways in which GLM principles can be embedded both inside and outside of the group room. For example, a diagram illustrating the GLM might be displayed in the group room and consistently revisited as clients check in and report back on progress associated with their intervention plans and GLPs. 
Finally, consistent with the GLM's emphasis on a client's social environment, wherever possible we advocate for generalizing GLM principles beyond the treatment room and into the environment in which a program operates - be it within a correctional facility or community-based case management system, for example. To reiterate, GLM-based intervention plans are concerned with equipping clients with the skills, knowledge, and resources to attain their prioritized goods in personally meaningful and socially acceptable ways. Offense-specific treatment comprises an important part of any intervention plan; however, successful attainment of prioritized goods also requires specified environmental resources and supports. To this end, involving multidisciplinary team members (i.e., correctional workers, nurses, healthcare workers, therapeutic activity workers) is crucial in ensuring the necessary environmental conditions are in place, as is establishing the external conditions and opportunities to ensure that clients can attain primary goods. The GLM provides a useful framework in which input from all professionals can be cohesively and systematically linked. For example, an offender who particularly values knowledge acquisition and the development of cultural expertise may have university teachers, local indigenous experts, his therapist, and support people on his intervention team. Accordingly, it is beneficial for all staff involved in a client's rehabilitation to be trained in the basic underpinnings of the GLM.

\section{Concluding Comments}

The GLM represents a contemporary, strengths-based approach to offender rehabilitation that complements the RNR by providing a more engaging, client-centered framework for sex offender treatment programs. Throughout this paper we have illustrated the clinical implications arising from a GLM framework as they relate to program aims and orientation, assessment, intervention planning, content, and delivery. It is important to 
emphasize that the GLM is a rehabilitation framework and, as such, is not therapeutically prescriptive. In concrete terms, this means that clinicians can exercise flexibility and creativity in determining how they integrate GLM ideas into their practice, so long as their approach is consistent with the guidelines we have offered, and that treatment addresses both risk reduction and goods attainment systematically. It is essential that the core constructs be imbedded throughout treatment, and not just as an additional module added to an existing program.

We acknowledge that external constraints such as resourcing and legislative demands might present barriers to fully integrating a GLM approach (Willis, et al., 2012). We also acknowledge that, while a growing body of empirical research supports the integration of GLM ideas and practices, whether increased responsiveness to the GLM (i.e., considering assessment, intervention planning, intervention content, and intervention delivery) enhances program outcomes remains unknown. Consistent and appropriate application of the GLM is a necessary precursor for such research. We hope that the guidelines we have offered will provide a useful platform for future research to investigate the effectiveness of GLM-based interventions.

It is too easy in today's political climate to confuse important social policy goals such as the reduction of offending rates with an overly restrictive, and at times, quite punitive intervention style. The social science literature is clear that human beings are far more responsive to inclusionary efforts and constructive approaches when challenged to change destructive social and personal behaviors, and their associated goals (Laws \& Ward, 2011). We all agree that treatment for sexual offending should aim to make the world a safer place for men, women and children, and therefore target each individual's array of dynamic risk factors. However, this does not mean that the needs of offenders, as fellow human beings, 
ought to be overlooked or their rights to lead better lives disregarded. A striking feature of strength-based intervention approaches such as the GLM is that they are able to address both the interests of offenders and the rest of the community at the same time. By offering offenders hope of more fulfilling lives, intervention can also ensure that their capacity to harm others is significantly diminished. 


\section{References}

Andrews, D. A., \& Bonta, J. (2006). The psychology of criminal conduct (4th ed.). Cincinnati, $\mathrm{OH}$ : Anderson Publishing.

Barnett, G., \& Wood, J. L. (2008). Agency, relatedness, inner peace, and problem solving in sexual offending: How sexual offenders prioritize and operationalize their good lives conceptions. Sexual Abuse: Journal of Research and Treatment, 20, 444-465. doi: $10.1177 / 1079063208325202$

Bonta, J., \& Andrews, D. A. (2010). Viewing offender assessment and rehabilitation through the lens of the risk-need-responsivity model. In F. McNeill, P. Raynor \& C. Trotter (Eds.), Offender Supervision: New Directions in Theory, Research and Practice (pp. 1940). Oxon, UK: Willan Publishing.

Frisch, M. B., Cornell, J., Villanueva, M., \& Retzlaff, P. J. (1992). Clinical validation of the Quality of Life Inventory. A measure of life satisfaction for use in treatment planning and outcome assessment. Psychological Assessment, 4, 92-101. doi: 10.1037/10403590.4.1.92

Gannon, T. A., King, T., Miles, H., Lockerbie, L., \& Willis, G. M. (2011). Good lives sexual offender treatment for mentally disordered offenders. British Journal of Forensic Practice, 13, 153-168. doi: 10.1108/14636641111157805

Gendreau, P., Goggin, C., \& Smith, P. (1999). The forgotten issue in effective correctional treatment: Program evaluation. International Journal of Offender Therapy and Comparative Criminology, 43, 180-187. 
Hanson, R. K., \& Bussiere, M. T. (1998). Predicting relapse: A meta-analysis of sexual offender recidivism studies. Journal of Consulting and Clinical Psychology, 66, 348362. doi: $10.1037 / 0022-006 X .66 .2 .348$

Hanson, R. K., Gordon, A., Harris, A. J. R., Marques, J. K., Murphey, W., Quinsey, V. L., et al. (2002). First report of the collaborative outcome data project on the effectiveness of psychological treatment for sex offenders. Sexual Abuse: A Journal of Research and Treatment, 14, 169194.

Hanson, R. K., Harris, A. J. R., Scott, T., \& Helmus, L. (2007). Assessing the risk of sexual offenders on community supervision: The Dynamic Supervision Project. Ottawa: Public Safety Canada.

Hanson, R. K., \& Morton-Bourgon, K. E. (2005). The characteristics of persistent sexual offenders: A meta-analysis of recidivism studies. Journal of Consulting and Clinical Psychology, 73, 1154-1163. doi: 10.1037/0022-006X.73.6.1154

Harkins, L., Flak, V. E., \& Beech, A. (in press). Evaluation of a community-based sex offender treatment program using a Good Lives Model approach. Sexual Abuse: A Journal of Research and Treatment.

Hayes, S. C., Strosahl, K., \& Wilson, K. G. (2011). Acceptance and Commitment Therapy: The Process and Practice of Mindful Change (2nd ed.). New York: Guilford Press

Helmus, L., Babchisin, K. M., Hanson, R. K., \& Thornton, D. (2010). Static-99R: Revised Age Weights. Retrieved from http://www.static99.org/pdfdocs/static99randage20091005.pdf

Kingston, D. A., Yates, P. M., Simons, D. A., \& Tyler, C. (2009, October). The Self-Regulation Model of sexual offender treatment: Relationship to risk and the Good Lives Model. 
Paper presented at the 28th Annual Convention of the Association for the Treatment of Sexual Abusers (ATSA), Dallas, TX.

Laws, D. R. (1989). Relapse prevention with sex offenders. New York: Guilford Press.

Laws, D. R., \& Ward, T. (2011). Desistance and sexual offending: Alternatives to throwing away the keys. New York, NY: Guildford Press.

Mann, R. E. (2009). Sex offender treatment: The case for manualization. Journal of Sexual Aggression, 15, 121-131. doi: 10.1080/13552600902907288

Mann, R. E., Webster, S. D., Schofield, C., \& Marshall, W. L. (2004). Approach versus avoidance goals in relapse prevention with sexual offenders. Sexual Abuse: A Journal of Research and Treatment, 16, 65-75.

Marshall, W. L. (2005). Therapist Style in Sexual Offender Treatment: Influence on Indices of Change. Sexual Abuse: Journal of Research and Treatment, 17, 109-116. doi: $10.1177 / 107906320501700202$

Marshall, W. L. (2009). Manualization: A blessing or a curse? Journal of Sexual Aggression, 15, 109-120. doi: 10.1080/13552600902907320

Marshall, W. L., \& Burton, D. L. (2010). The importance of group processes in offender treatment. Aggression and Violent Behavior, 15, 141-149. doi: 10.1016/j.avb.2009.08.008

Marshall, W. L., Marshall, L. E., Serran, G. A., \& O'Brien, M. D. (2011). Rehabilitating sexual offenders: A strength-based approach. Washington, DC: American Psychological Association.

Marshall, W. L., O'Brien, M. D., \& Marshall, L. E. (2009). Modifying sexual preferences. In A. Beech, L. A. Craig \& K. D. Browne (Eds.), Assessment and treatment of sex offenders: a handbook (pp. 311-327). Chichester, England: Wiley. 
McGrath, R., Cumming, G., Burchard, B., Zeoli, S., \& Ellerby, L. (2010). Current practices and emerging trends in sexual abuser management: The Safer Society 2009 North American survey. Brandon, Vermont: Safer Society Press.

Miller, W. R., \& Rollnick, S. (Eds.). (2002). Motivational Interviewing: Preparing people for change (2nd ed.). New York, NY: Guildford Press.

Purvis, M. (2010). Seeking a Good Life: Human Goods and Sexual Offending. Germany: Lambert Academic Press.

Scoones, C., Willis, G. M., \& Grace, R. C. (2012). Beyond static and dynamic risk factors: the incremental predictive validity of release planning in sex offender risk assessment. Journal of Interpersonal Violence, 27, 222 - 238.

Sellen, J. L., McMurran, M., Cox, W. M., Theodosi, E., \& Klinger, E. (2006). The personal concerns inventory (offender adaptation): measuring and enhancing motivation to chance. International Journal of Offender Therapy and Comparative Criminology, 50, 294-305. doi: 10.1177/0306624X05281829

Simons, D. A., McCullar, B., \& Tyler, C. (2006, September). Evaluation of the Good Lives Model approach to treatment planning. Paper presented at the 25th Annual Association for the Treatment of Sexual Abusers Research and Treatment Conference, Chicago, Illinois.

Thornton, D. (1997, October). Is relapse prevention really necessary? Paper presented at the the meeting of the Association for the Treatment of Sexual Abusers, Arlington, VA.

Ward, T. (2002). Good lives and the rehabilitation of offenders: promises and problems. Aggression and Violent Behavior, 7, 513-528. doi: 10.1016/S1359-1789(01)00076-3 
Ward, T., \& Gannon, T. A. (2006). Rehabilitation, etiology, and self-regulation: The comprehensive good lives model of treatment for sexual offenders. Aggression and Violent Behavior, 11, 77-94. doi: 10.1016/j.avb.2005.06.001

Ward, T., \& Hudson, S. M. (1998). A model of the relapse process in sexual offenders. Journal of Interpersonal Violence, 13, 700-725.

Ward, T., \& Mann, R. (2004). Good lives and the rehabilitation of offenders: A positive approach to treatment. In A. Linley \& S. Joseph (Eds.), Positive psychology in practice (pp. 598-616). Hoboken, NJ: John Wiley \& Sons.

Ward, T., Mann, R. E., \& Gannon, T. A. (2007). The good lives model of offender rehabilitation: Clinical implications. Aggression and Violent Behavior, 12, 87-107. doi: 10.1016/j.avb.2006.03.004

Ward, T., \& Maruna, S. (2007). Rehabilitation: Beyond the risk assessment paradigm. London, UK: Routledge.

Ward, T., Melser, J., \& Yates, P. M. (2007). Reconstructing the Risk Need Responsivity Model: A theoretical elaboration and evaluation. Aggression and Violent Behavior, 12, 208228. doi: 10.1016/j.avb.2006.07.001

Ward, T., \& Stewart, C. A. (2003). The treatment of sex offenders: Risk management and good lives. Professional Psychology: Research and Practice, 34, 353-360. doi: $10.1037 / 0735-7028.34 .4 .353$

Ward, T., \& Syversen, K. (2009). Human dignity and vulnerable agency: An ethical framework for forensic practice. Aggression and Violent Behavior, 14, 94-105. doi: 10.1016/j.avb.2008.12.002 
Ward, T., Yates, P. M., \& Long, C. A. (2006). The Self-Regulation Model of the Offence and Relapse Process, Volume II: Treatment. Victoria, BC: Pacific Psychological Assessment Corporation. Available at www.pacific-psych.com.

Ward, T., Yates, P. M., \& Willis, G. M. (2012). The Good Lives Model and the Risk Need Responsivity Model: A critical response to Andrews, Bonta, and Wormith (2011). Criminal Justice and Behavior, 39, 94-110.

Willis, G. M., \& Grace, R. C. (2008). The quality of community reintegration planning for child molesters: effects on sexual recidivism. Sexual Abuse: A Journal of Research and Treatment, 20, 218-240. doi: 10.1177/1079063208318005

Willis, G. M., \& Grace, R. C. (2009). Assessment of community reintegration planning for sex offenders: poor planning predicts recidivism. Criminal Justice and Behavior, 36, 494512. doi: $10.1177 / 0093854809332874$

Willis, G. M., \& Ward, T. (2011). Striving for a good life: The Good Lives Model applied to released child molesters. Journal of Sexual Aggression, 17, 290-303. doi: $10.1080 / 13552600.2010 .505349$

Willis, G. M., Ward, T., \& Levenson, J. S. (2012). Evaluation of sex offender treatment program responsiveness to the Good Lives Model. Manuscript in preparation.

Yates, P. M. (2007). Taking the leap: Abandoning relapse prevention and applying the selfregulation model to the treatment of sexual offenders In D. S. Prescott (Ed.), Applying Knowledge to Practice: The Treatment And Supervision of Sexual Abusers. (pp. 143-174). Oklahoma City, OK: Wood N Barnes.

Yates, P. M. (2009). Using the Good Lives Model to motivate sexual offenders to participate in treatment. In D. S. Prescott (Ed.), Building Motivation to Change in Sexual Offenders. Brandon, VT: Safer Society Press. 
Yates, P. M., Goguen, B. C., Nicholaichuk, T. P., Williams, S. M., Long, C. A., Jeglic, E. L., et al. (2000). National Sex Offender Programs (Moderate, Low, and Maintenance Intensity Levels). Ottawa: Correctional Service of Canada.

Yates, P. M., \& Kingston, D. A. (2011). Pathways to sexual offending. In B. K. Schwartz (Ed.), Handbook of Sexual Offender Treatment (Vol. 17, pp. 1-16). Kingston, NJ: Civic Research Institute.

Yates, P. M., Kingston, D. A., \& Ward, T. (2009). The Self-Regulation Model of the offence and re-offence process: A guide to assessment and treatment planning using the integrated Good Lives / Self-Regulation Model of sexual offending. Victoria, BC: Pacific Psychological Assessment Corporation.

Yates, P. M., \& Prescott, D. S. (2011). Preventing sexual re-offending: A workbook for building a better life. Brandon, VT: Safer Society Press.

Yates, P.M. \& Prescott, D.S. (2012). Applying the Good Lives Model to Clinical Practice: Redefining Primary Human Goods. Newsletter of the National Organisation for the Treatment of Abusers (NOTA) (http://www.nota.co.uk/).

Yates, P. M., Prescott, D. S., \& Ward, T. (2010). Applying the Good Lives and Self Regulation Models to sex offender treatment: a practical guide for clinicians. Brandon, VT: Safer Society Press.

Yates, P. M., Simons, D. A., Kingston, D. A., \& Tyler, C. (2009, October). The Good Lives Model of rehabilitation applied to treatment: Assessment and relationship to treatment progress and compliance. . Paper presented at the 28th Annual Convention of the Association for the Treatment of Sexual Abusers (ATSA), Dallas, TX. 
Yates, P. M., \& Ward, T. (2007). Treatment of sexual offenders: Relapse prevention and beyond. In K. Witkiewitz \& G. A. Marlatt (Eds.), Therapists' Guide to Evidence-Based Relapse Prevention (pp. 215-234). Burlington, MA: Elsevier Press.

Yates, P. M., \& Ward, T. (2008). Good lives, self-regulation, and risk management: An integrated model of sexual offender assessment and treatment. Sexual Abuse in Australia and New Zealand: An Interdisciplinary Journal, 1, 3-20. 